\title{
A Novel Mutation in Exon 6 of the Epsilon-Sarcoglycan Gene in Myoclonus Dystonia Syndrome
}

Hulya Apaydin', Gulcin Benbir ${ }^{1 *}$, Laurie Ozelius² and Sibel Ozekmekci ${ }^{1}$

${ }^{1}$ Department of Neurology, Cerrahpasa Faculty of Medicine, Istanbul University, Istanbul, Turkey

${ }^{2}$ Department of Genetics and Genomic Sciences, Mount Sinai School of Medicine, New York, NY, USA

\begin{abstract}
Myoclonus-dystonia syndrome (MDS) is a rare hereditary movement disorder characterized by the early onset of myoclonus in the first or second decade of life. The first locus for MDS was mapped to chromosome 7q21 and identified as the epsilon-sarcoglycan (SGCE) gene, and numerous mutations were subsequently identified. We here present the first reported Turkish MDS patient identified with a novel mutation in exon 6 of the SGCE gene, which resulted in truncation of the protein before the transmembrane domain, presumably causing the loss of function either by mislocalization of the protein away from the plasma membrane or through nonsense-mediated decay.
\end{abstract}

Keywords: Myoclonus-dystonia syndrome; Epsilon-sarcoglycan gene; Exon 6; Novel mutation

\section{Introduction}

Myoclonus-dystonia syndrome (MDS) is a rare hereditary movement disorder. The first definition of this syndrome was made in a large German family as "myoclonic dystonia with lightning jerks responsive to alcohol" [1]. It is characterized by the early onset of myoclonus in the first or second decade of life, frequently accompanied by dystonia involving the neck, arms, and face. The severity of MDS varies ranging from mild subtle features, to marked impairment due to severe myoclonus and/or dystonia [2]. On the other hand, patients generally have a normal life-span. Alleviation of symptoms in response to alcohol but not to L-dopa is well established even though the response to treatment varies.

Segregation analysis in MDS families showed autosomal dominant inheritance with reduced penetrance, but the syndrome also occurs sporadically. Mutations in the epsilon-sarcoglycan (SGCE) gene were identified as a cause for MDS [3]. Here we present the first reported Turkish MDS patient with a novel nonsense mutation in exon 6 of the SGCE gene.

\section{Case Report}

A 22-year-old, right-handed man was admitted with involuntary twisting movements of the hands and head causing adduction of the arms, and deviation of the neck to the right-side and backwards; which started at the age of 4 years, showed some progression, but then remained stationary for years. The patient stated that these movements caused dropping objects, interfered with writing and walking, and worsened with stress or attempts to write. He refused to take alcoholic beverages to test the response.

His past medical history was unremarkable. He was born after a normal pregnancy and delivery; his psychomotor development was normal. His family history was negative for any movement disorders; there was no consanguinity. His neurological examination revealed retrocollis, dystonic hyperextension posture and myoclonic jerks involving his trunk and both arms being more prominent on the left side with hypertrophia of the affected muscles (Figure 1) which worsened with action (Video segment). The patient was given a variety of drugs including: haloperidol, biperiden, clonazepam, piracetam, levetiracetam, olanzapine, venlafaxine, sodium valproate and diazepam, with either no or limited effect. He was then treated with botulinum toxin-A for selected dystonic muscle groups, which resulted in significant relief. On his last examination, retrocollis was obviously decreased; some difficulties with the hand movements and writing were still present.

Biochemical tests and cranial magnetic resonance imaging were normal. We obtained informed consent from the patient for DNA analysis. The DNA sample was screened for mutations in the SGCE gene by direct sequencing using previously published primers and conditions [4], and a novel nonsense mutation, c.727 C>T; p.Q243X, was identified in exon 6 .

\section{Discussion}

Our patient presented with clinically typical MDS characterized by dystonia and myoclonus of the upper body. The full phenotypic spectrum of this syndrome, however, is quite diverse and still being defined $[2,5]$. Although early disease onset, onset with both myoclonus and dystonia, and axial dystonia were detected significantly more often in the mutation carriers [6], there has been no clear phenotypegenotype associations identified to date suggesting other genetic or environmental factors as modifiers.

The first locus for MDS was mapped to chromosome $7 \mathrm{q} 21$ and identified as the epsilon-sarcoglycan gene $[1,3]$. Subsequently, numerous mutations in this gene have been described [5]. A second MDS locus was mapped to chromosome 18p11 [7]. Mutations in SGCE are usually associated with familial MDS cases [8]. Recently, MDS in a patient with $18 \mathrm{p}$ deletion syndrome was also described [9]. A few sporadic cases with de novo SGCE mutation have also been reported [5]. Different genetic mutations in exon 3, exon 4, and also in exon 6 were previously reported underlying the importance to register novel mutations and to add them to the preexisting list of known mutations in order to ensure an as fast and cost-effective diagnostic procedure as possible $[4,8,10,11]$. The authors suggested that exon rearrangement results in the generation of premature stop codons downstream of the deleted exon. We identified a novel mutation in exon 6 of the SGCE

*Corresponding author: Gulcin Benbir, Istanbul University Cerrahpasa Faculty of Medicine, Department of Neurology, 34098, Istanbul, Turkey, Tel: +90 (533) 226 37 97; Fax: +90 (212) 63296 96; E-mail: drgulcinbenbir@yahoo.com

Received January 10, 2012; Accepted June 06, 2012; Published June 10, 2012

Citation: Apaydin H, Benbir G, Ozelius L, Ozekmekci S (2012) A Novel Mutation in Exon 6 of the Epsilon-Sarcoglycan Gene in Myoclonus Dystonia Syndrome. Hereditary Genet 1:110. doi:10.4172/2161-1041.1000110

Copyright: (c) 2012 Apaydin H, et al. This is an open-access article distributed under the terms of the Creative Commons Attribution License, which permits unrestricted use, distribution, and reproduction in any medium, provided the original author and source are credited. 

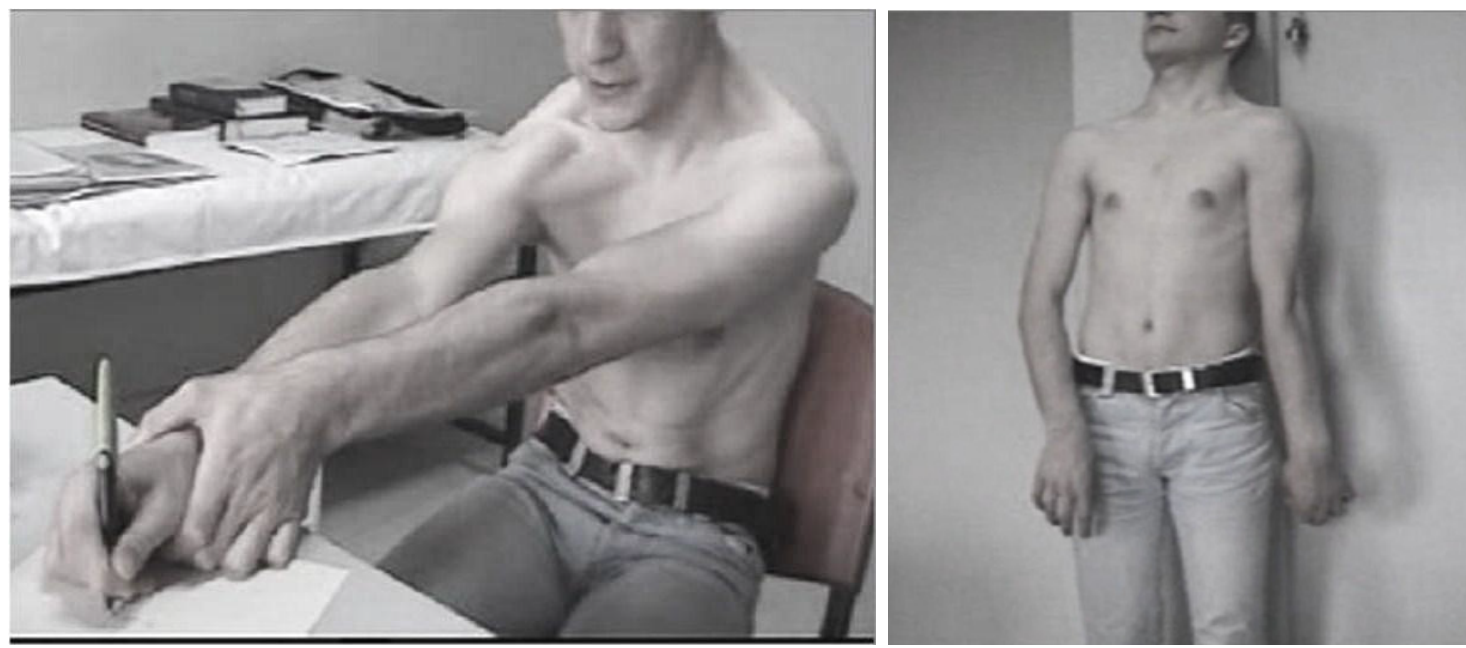

Figure 1. Retrocollis, dystonia on his trunk and both arms being more prominent on left side, worsening with purposeful movements, and hypertrophia of the affected muscles were observed.

gene in the first Turkish patient described with MDS. The mutation, Q243X, results in a truncation of the protein before the transmembrane domain presumably causing loss of function either by mislocalization of the protein away from the plasma membrane or through nonsensemediated decay. The location (extracellular domain) and mutational mechanism (loss of function) described in this patient, are typical of different mutations previously found in this gene [5]. SGCE exon dosage assays may identify other SGCE mutations, and may help better definition of phenotype-genotype correlation.

\section{References}

1. Gasser T, Bereznai B, Muller B, Pruszak-Seel R, Damrich R, et al. (1996) Linkage studies in alcohol-responsive myoclonic dystonia. Mov Disord 11: 363370.

2. Marechal L, Raux G, Dumanchin C, Lefebre G, Deslandre E, et al. (2003) Severe myoclonus-dystonia syndrome associated with a novel epsilonsarcoglycan gene truncating mutation. Am J Med Genet B Neuropsychiatr Genet 119: 114-117.

3. Zimprich A, Grabowski M, Asmus F, Naumann M, Berg D, et al. (2001) Mutations in the gene encoding epsilon-sarcoglycan cause myoclonus-dystonia syndrome. Nat Genet 29: 66-69.
4. Asmus F, Salih F, Hjermind LE, Ostergaard K, Munz M, et al. (2005) Myoclonusdystonia due to genomic deletions in the epsilon-sarcoglycan gene. Ann Neuro 58: 792-797.

5. Kinugawa K, Vidailhet M, Clot F, Apartis E, Grabli D, et al. (2009) Myoclonusdystonia: an update. Mov Disord 24: 479-489.

6. Gerrits MC, Foncke EM, de Haan R, Hedrich K, van de Leemput YL, et al (2006) Phenotype-genotype correlation in Dutch patients with myoclonusdystonia. Neurology 66: 759-761.

7. Grimes DA, Han F, Lang AE, St George-Hyssop P, Racacho L, et al. (2002) A novel locus for inherited myoclonus-dystonia on 18p11. Neurology 59: 11831186.

8. Asmus F, Langseth A, Doherty E, Nestor T, Munz M, et al. (2009) "Jerky" Dystonia in Children: Spectrum of Phenotypes and Genetic Testing. Mov Disord 24: 702-709.

9. Kowarik MC, Langer S, Keri C, Hemmer B, Oexle K, et al. (2011) MyoclonusDystonia in 18p Deletion Syndrome. Mov Disord 26: 560-561.

10. Hartman CJ, Leube B, Wojtecki L, Betz B, Groiss SJ, et al. (2011) A nove mutation of the SGCE-gene in a German family with myoclonus-dystonia syndrome. J Neurol 258: 1186-1188.

11. Tedroff K, Rolfs A, Norling A (2012) A novel SGCE gene mutation causing myoclonus dystonia in a family with an unusual phenotype. Acta Pediatr 101: e90-92. 